\title{
Phylogenetic analysis of some Aerococcus-like organisms from urinary tract infections: description of Aerococcus urinae sp. nov.
}

\author{
Maria Aguirre and Matthew D. Collins* \\ Department of Microbiology, AFRC Institute of Food Research, Reading Laboratory, Shinfield, Reading RG2 9AT, UK
}

(Received 15 August 1991; revised 26 September 1991; accepted 21 October 1991)

\begin{abstract}
Partial 16S ribosomal ribonucleic acid sequences of five Aerococcus-like organisms originally isolated from patients with urinary tract infections were determined using reverse transcriptase in order to clarify their taxonomic position. Analysis of the sequence data revealed that the clinical isolates represent a hitherto unknown line of descent within the genus Aerococcus. A new species, Aerococcus urinae, is proposed for these isolates. The type strain is NCFB 2893.
\end{abstract}

\section{Introduction}

The genus Aerococcus was proposed by Williams et al. (1953) to accommodate some Gram-positive, microaerophilic, catalase-negative bacteria which differed from streptococci primarily by their characteristic tetrad cellular arrangements. Currently, the genus comprises a single species, Aerococcus viridans (Evans, 1986). Aerococci are widely distributed and occur naturally in air, dust and vegetation; they also form part of the flora of meat-curing brines (Deibel \& Niven, 1960). Although aerococci are generally considered saprophytic, some are pathogenic for lobsters (Hitchner \& Snieszko, 1947) and there have been various reports of Aerococcus-like organisms from human infections (e.g. subacute bacterial endocarditis: Colman, 1967; Janosek et al., 1980; Parker \& Ball, 1976; urinary tract infections: Colman, 1967; bacteraemia: Taylor \& Trueblood, 1985; and meningitis: Nathavitharana et al., 1983). The identification of aerococci is complex, due to the paucity of reliable discriminatory phenotypic traits. Their most characteristic feature is their tendency to divide in two planes at right angles to form tetrads. Aerocci also exhibit many biochemical and physiological similarities with pediococci, enterococci, lactococci and leuconostocs, and are often confused with streptococci (Facklam et al., 1989). Problems with the identification of aerococci are further

* Author for correspondence. Tel. (0734) 883103; fax (0734) 884763.

Abbreviation: ALO, Aerococcus-like organism.

The nucleotide sequence data reported in this paper have been submitted to GenBank and have been assigned the accession number M77819. compounded by evidence of some genetic heterogeneity within the species (Bosley et al., 1990; Wiik et al., 1986).

Christensen et al. $(1989,1991)$ recently reported the isolation and characterization of some Aerococcus-like organisms (ALOs) from urine samples of patients with urinary tract infections. These clinical ALOs differed from typical Aerococcus viridans strains in several phenotypic tests and their precise taxonomic status remained uncertain. $16 \mathrm{~S}$ rRNA sequencing studies have done much to clarify the inter- and intra-generic relationships of aerococci, pediococci, streptococci and other lactic acid bacteria (Bentley et al., 1991; Collins et al., 1989, 1990, 1991; Martinez Murcia \& Collins, 1990; Williams et al., 1991; Yang \& Woese, 1989). Therefore, in the present study we have investigated the partial $16 \mathrm{~S}$ rRNA sequences of five ALOs from urinary tract infections (Christensen et al., 1989, 1991) in an attempt to determine their true phylogenetic position.

\section{Methods}

Cultures and cultivation. Five strains, designated E2, E3, B3, I3 and ES4, originally isolated from urine specimens, were received from $\mathrm{Dr} J$. J. Christensen (Bispebjerg Hospital, Copenhagen, Denmark). The isolates were grown on blood agar plates and, for nucleic acid analysis, in glucose/yeast extract/phosphate broth (Garvie, 1978) at $37^{\circ} \mathrm{C}$. Cultures were harvested by centrifugation in late exponential phase and washed in deionized water.

Analysis of $16 S \mathrm{rRNA}$. Cells (about $2 \mathrm{~g}$ ) were mechanically broken using a Braun homogenizer, and RNA purified according to the procedure of Embley et al. (1988). Nucleotide sequences were determined by the dideoxynucleotide chain-termination method (Sanger et al., 1977) directly from rRNA using AMV reverse transcriptase (Lane $e t$ al., 1985). Nucleotide fragments produced in the 
chain-elongation reactions were separated on $55 \mathrm{~cm}$ wedge-shaped $6 \%$ (w/v) acrylamide/7 M urea gels at $55^{\circ} \mathrm{C}$ using an LKB Macrophor 2010 sequencing unit operated at $50 \mathrm{~W}$ per gel.

The sequences generated were aligned, and homology values determined by the Beckman Microgenie Program (Queen \& Korn, 1984). Nucleotide substitution rates ( $K_{n u c}$ values) were calculated and an unrooted phylogenetic tree produced using the algorithm of Fitch \& Margoliash (1967).

Biochemical tests. Biochemical tests were performed on the five clinical strains and the type strain of Aerococcus viridans (NCDO 1225) by using the API 20 STREP and $50 \mathrm{CH}$ systems according to the manufacturer's instructions. Blood agar was used as basal medium. Test preparations were incubated at $37^{\circ} \mathrm{C}$ and read after 4,24 and $48 \mathrm{~h}$.

\section{Results and Discussion}

The partial 16S rRNA nucleotide sequence from ALO strain E2 was determined using reverse transcriptase. The sequence is shown in Fig. 1; it consisted of a continuous stretch of 1481 nucleotides representing about $96 \%$ of the total molecule. The first and last nucleotides in the sequence correspond to positions 8 and 1482 of the Escherichia coli numbering system (Brosius et al., 1978). The primary structures of two short fragments (approx. positions 50 to 450, which includes variable regions $\mathrm{V} 1$ and $\mathrm{V} 2$; and positions 950 to 1210 , which includes variable region V6; see Neefs et al., 1990, for nomenclature) of the 16S rRNA of four other ALOs (strains E3, B3, I3 and ES4) were also determined and found to be identical to that of strain E2, thereby confirming the genetic relatedness of the five clinical isolates.

In order to determine the taxonomic position of the clinical ALOs, the sequence of strain E2 was aligned and compared with those of Aerococcus viridans and 27 reference strains representing 14 low-mol\% $\mathrm{G}+\mathrm{C}$ genera. Percentage sequence similarities, shown in Table 1 , were calculated from a continuous region of 1340 nucleotides (ranging from positions 107 to 1433 of the $E$. coli sequence). Approximately 100 nucleotides at the $5^{\prime}$ end of the rRNA molecule were not included in the calculation to eliminate possible alignment errors due to the extremely variable V1 region (Neefs et al. 1990) and to ensure that only homologous positions were compared. The unknown isolate exhibited the highest similarity $(94.5 \%)$ with $A$. viridans. High sequence similarities (approx. 91 to $92 \%$ ) were also shown with carnobacteria, enterococci and vagococci, but significantly lower values (approx. 88 to $90 \%$ ) were shared with lactobacilli, pediococci and streptococci. Some representative sequence homologies are shown in Table 1. A phylogenetic tree constructed from a matrix of derived $K_{\text {nuc }}$ values using the Fitch and Margolish algorithm is shown in Fig. 2. In this scheme, the unknown clinical bacterium showed a close affinity with $A$. viridans, and clearly represents a second line within the genus Aerococcus. The five ALOs possessed identical biochemical profiles using the API 20 STREP and $50 \mathrm{CH}$ systems. The type strain of $A$. viridans differed from these strains in several tests. Differential tests are shown in Table 2.

Phylogenetic studies have shown that the genus Aerococcus represents a distinct line of descent within the lactic acid bacteria (Collins et al., 1990, 1991). Currently the genus consists of a single species, $A$. viridans (Evans, 1986). There is, however, indication of some heterogeneity within aerococci. In an investigation of aerococci from clinical sources Bosley et al. (1990) reported that two groups were discernible within $A$. viridans on the basis of DNA-DNA pairing. The two groups, however, possessed very high overall chromosomal DNA sequence relatedness (60 to $78 \%$ homology under optimal hybridization conditions) and were phenotypically indistinguishable. 16S rRNA sequencing studies confirmed the close affinity between these two groups, with only two base differences detected for a comparison of 1486 nucleotides between $A$. viridans and a representative strain of the second DNA homology group (Collins et al.,

\begin{abstract}
AGAGUUUGAUCCUGGCUCAGGACGAACGCUGGCGGCGUGCCUAAUACAUGCAAGUCGAGCGAACCGACGAAGUGCUUGCACUUCUGACGUUAGCGGCGGA CGGGUGAGUAACACGUAAGGAACCUACCGAUAAGCGGGGGACAACAUCCGGAAACGGGUGCUAAUACCGCAUAGGAAAGGUCACCNCAUGGUGACCUUUG GAAAGACGGCUUUGCUGUCACUUAUCGAUGGCCUUGCNGUGCAUUAGCUCGUUGGUGGGGUAACGGCCUACCAAGGCAAUGAUGCAUAGCCGACCUGAGA GGGUAAUCGGCCACAUUGGGACUGAGACACGGCCCAAACUCCUACGGGAGGCAGCAGUAGGGAAUCUUCCGCAAUGGGCGCAAGCCUGACGGAGCAACGC CGCGUGAGUGAAGAAGGUUUUCGGAUCGUAAAGCUCUGUUGUAAGAGAAGAACAAAUUGGAGAGUAACUGCUCCAGUCUUGACGGUAUCUUACCAGAAAG CCACGGCUAACUACGUGCCAGCAGCCGCGGUAAUACGUAGGUGGCAAGCGUUGUCCGGAUUUAUUGGGCGUAAAGGGGGCGCAGGCGGUUUCUUAAGUCU GAUGUGAAAGCCCACGGCUUAACCGUGGAAGUGCAUUGGAAACUGGGNAACUUGAGUACAGAAGAGGAAAGUGGAACUCCAUGUGUAGCGGUGGAAUGCG UAGAUAUAUGGAAGAACA CAGUGGCGAAGGCGACUUUCUGGUCUGUCACUGACGCUGAGGCCCGAAAGCGUGGGUAGCAAACAGGAUUAGAUACCCUGG UAGUCCACGCCGUAAACGAUGAGUGCUANGUGUUGGAGGGUUUCCACCCUUCAGUGCCGGAGUUAACGCAUUAAGCACUCCGCCUGGGGAGUACGGCCGC AAGGCUGAAACUCAAAGGAAUUGACGGGGACCGCACAAGCGGUGGAGCAUGUGGUUUAAUUCGAAGCAACGCGAAGAACCUUACCAAGUCUUGACAUCCG UUGACCACUCUAGAGAUAGAGCUUUCUUCGGGGACNAAGUGACAGGUGGUGCAUGGUUGUCGUCAGCUCGUGUCGUGAGAUGUUGGGUUAAGUCCCGCAA CGAGCGCAACCCUUAUUGUUAGUUGCCAGCAUUNAGUUGGGCACUCUAGCGAGACUGCCGGUGACAAACCGGAGGAAGGCGGGGAUGACGUCAAAUCAUC AUGCCCCUUAUGACUUGGGCUACACACGUGCUACAAUGGAUGGUACAAEGAGUCAGCGACCUUGUGAAAGCAAGCGAAUCUCUUAAAGCCAUUCUCAGUU CGGAUUGUAGUCUGCAACUCGACUACAUGAAGCCGGAAUCGCUAGUAAUCGCGGAUCAGCACGCCGCGGUGAAUACGUUCCCGGGUCUUGUACACACCGC CCGUCACACCACGAGAGUUUGUAACACCUGAAGUCGGUGAGGUAACCUUUGGAGCCAGCCGCCGAAGGUNNGACAGAUAUU
\end{abstract}

Fig. 1. Primary structure of $16 \mathrm{~S}$ rRNA from Aerococcus urinae (NCFB 2893) determined using reverse transcriptase. N, undetermined nucleotide. The number of the nucleotide at the beginning of each line in the sequence corresponds to the $E$. coli numbering system (Brosius et al., 1978). 
Table 1. Homology (lower left-hand triangle) and $K_{\text {nuc }}$ values (upper right-hand triangle) for a 1340-nucleotide region of $16 S$ rRNAs of Aerococcus urinae and other taxa

\begin{tabular}{|c|c|c|c|c|c|c|c|c|c|c|c|c|c|c|}
\hline & 1 & 2 & 3 & 4 & 5 & 6 & 7 & 8 & 9 & 10 & 11 & 12 & 13 & 14 \\
\hline $\begin{array}{l}\text { 1. Aerococcus urinae } \\
\text { NCFB } 2893^{\mathrm{T}} \text { (=ALO E2) }\end{array}$ & $\cdot$ & 0.0571 & $0 \cdot 1225$ & 0.1284 & 0.0812 & 0.0891 & 0.1260 & 0.1513 & $0 \cdot 1428$ & $0 \cdot 1120$ & $0 \cdot 1085$ & $0 \cdot 1143$ & $0 \cdot 1260$ & 0.0925 \\
\hline $\begin{array}{l}\text { 2. Aerococcus viridans } \\
\text { NCDO } 1225^{\mathrm{T}}\end{array}$ & $94 \cdot 5$ & $\cdot$ & 0.1355 & 0.1190 & 0.0790 & 0.0812 & 0.1476 & $0 \cdot 1260$ & $0 \cdot 1367$ & $0 \cdot 1050$ & $0 \cdot 1143$ & $0 \cdot 1004$ & $0 \cdot 1225$ & 0.0768 \\
\hline $\begin{array}{l}\text { 3. Bacillus subtilis } \\
\text { rrNB }\end{array}$ & $88 \cdot 7$ & $87 \cdot 6$ & $\cdot$ & 0.1143 & $0 \cdot 1062$ & $0 \cdot 1004$ & $0 \cdot 1274$ & 0.1537 & $0 \cdot 1636$ & 0.0868 & 0.1225 & $0 \cdot 0891$ & $0 \cdot 1476$ & $0 \cdot 1131$ \\
\hline $\begin{array}{l}\text { 4. Brochothrix thermosphacta } \\
\text { NCDO } 1676^{T}\end{array}$ & $88 \cdot 2$ & $89 \cdot 0$ & 89.4 & $\cdot$ & $0 \cdot 1050$ & 0.0925 & $0 \cdot 1525$ & $0 \cdot 1464$ & $0 \cdot 1649$ & 0.0724 & 0.1213 & $0 \cdot 1096$ & 0.1331 & 0.0936 \\
\hline $\begin{array}{l}\text { 5. Carnobacterium divergens } \\
\text { NCDO } 2763^{\mathrm{T}}\end{array}$ & $92 \cdot 3$ & $92 \cdot 5$ & $90 \cdot 1$ & $90 \cdot 2$ & $\cdot$ & 0.0560 & 0.1331 & 0.1343 & 0.1476 & 0.0846 & 0.0835 & $0 \cdot 1096$ & 0.1154 & 0.0658 \\
\hline $\begin{array}{l}\text { 6. Enterococcus cecorum } \\
\text { NCDQ } 2674^{\mathrm{T}}\end{array}$ & $91 \cdot 6$ & $92 \cdot 3$ & $90 \cdot 6$ & $91 \cdot 3$ & $94 \cdot 6$ & $\cdot$ & 0.1154 & 0.1004 & $0 \cdot 1331$ & 0.0824 & 0.0835 & $0 \cdot 1050$ & $0 \cdot 1027$ & 0.0593 \\
\hline $\begin{array}{l}\text { 7. Lactobacillus acidophilus } \\
\text { NCDO } 1748^{\mathrm{T}}\end{array}$ & $88 \cdot 4$ & 86.6 & $88 \cdot 3$ & $86 \cdot 2$ & $87 \cdot 8$ & $89 \cdot 3$ & $\cdot$ & $0 \cdot 1661$ & $0 \cdot 1296$ & $0 \cdot 1428$ & $0 \cdot 1131$ & $0 \cdot 1574$ & 0.1416 & 0.1272 \\
\hline $\begin{array}{l}\text { 8. Lactococcus garvieae } \\
\text { NCDO } 2155^{\mathrm{T}}\end{array}$ & $86 \cdot 3$ & 88.4 & $86 \cdot 1$ & 86.7 & $87 \cdot 7$ & $90 \cdot 6$ & $85 \cdot 1$ & $\cdot$ & 0.1599 & $0 \cdot 1440$ & $0 \cdot 1201$ & $0 \cdot 1699$ & 0.0902 & 0.1331 \\
\hline $\begin{array}{l}\text { 9. Leuconostoc mesenteroides } \\
\text { NCDO } 523^{\mathrm{T}}\end{array}$ & 87.0 & $87 \cdot 5$ & $85 \cdot 3$ & $85 \cdot 2$ & $86 \cdot 6$ & $87 \cdot 8$ & $88 \cdot 1$ & 85.6 & · & $0 \cdot 1537$ & 0.1476 & $0 \cdot 1686$ & $0 \cdot 1488$ & 0.1428 \\
\hline $\begin{array}{l}\text { 10. Listeria innocua } \\
\text { NCTC } 11288^{\mathrm{T}}\end{array}$ & $89 \cdot 6$ & $90 \cdot 2$ & 91.8 & $93 \cdot 1$ & $92 \cdot 0$ & $92 \cdot 2$ & 87.0 & 86.9 & $86 \cdot 1$ & $\cdot$ & $0 \cdot 1108$ & $0 \cdot 1027$ & $0 \cdot 1320$ & 0.0947 \\
\hline $\begin{array}{l}\text { 11. Pediococcus acidilactici } \\
\text { NCFB } 2767^{\top}\end{array}$ & 89.9 & 89.4 & 88.7 & $88 \cdot 8$ & $92 \cdot 1$ & $92 \cdot 1$ & $89 \cdot 5$ & 88.9 & $86 \cdot 6$ & $89 \cdot 7$ & $\cdot$ & 0.1272 & $0 \cdot 1225$ & 0.0925 \\
\hline 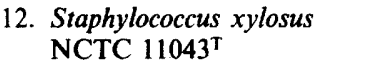 & 89.4 & $90 \cdot 6$ & $91 \cdot 6$ & $89 \cdot 8$ & $89 \cdot 8$ & $90 \cdot 2$ & 85.8 & 84.8 & 84.9 & 90.4 & $88 \cdot 3$ & $\cdot$ & $0 \cdot 1550$ & $0 \cdot 1120$ \\
\hline $\begin{array}{l}\text { 13. Streptococcus pyogenes } \\
\text { NCDO } 2381^{\mathrm{T}}\end{array}$ & 88.4 & 88.7 & $86 \cdot 6$ & 87.8 & $89 \cdot 3$ & $90 \cdot 4$ & $87 \cdot 1$ & $91 \cdot 5$ & $86 \cdot 5$ & $87 \cdot 9$ & $88 \cdot 7$ & 86.0 & . & $0 \cdot 1260$ \\
\hline $\begin{array}{l}\text { 14. Vagococcus fluvialis } \\
\text { NCDO } 2497^{\mathrm{T}}\end{array}$ & $91 \cdot 3$ & $92 \cdot 7$ & $89 \cdot 5$ & $91 \cdot 2$ & 93.7 & $94 \cdot 3$ & $88 \cdot 3$ & 87.8 & $87 \cdot 0$ & $91 \cdot 1$ & $91 \cdot 3$ & $89 \cdot 6$ & $89 \cdot 0$ & $\cdot$ \\
\hline
\end{tabular}

Table 2. Characteristics useful in differentiating $A$. urinae and $A$. viridans

Data were obtained using the API 20STREP and $50 \mathrm{CH}$ systems; results are for five strains of $A$. urinae and the type strain of $A$. viridans.

\begin{tabular}{lcc}
\hline \hline \multicolumn{1}{c}{ Test } & A. urinae & A. viridans \\
\hline Production of: & & \\
$\beta$-Galactosidase & + & + \\
$\beta$-Glucuronidase & - & + \\
Pyrrolidonylarylamidase & + & - \\
Leucine aminopeptidase & - & + \\
Acid production from: & - & + \\
Lactose & + & - \\
Glycerol & & \\
Sorbitol & & \\
\hline
\end{tabular}

1990). The results of the present study clearly demonstrate that the human ALOs isolated by Christensen et al. $(1989,1991)$ from urinary tract infections are distinct from the $A$. viridans and genotype 2 of Bosley et al (1990). The 16S rRNA of ALO strain E2 showed 74 base differences with that of the type strain of $A$. viridans (based on a comparison of the same 1486 nucleotide stretch). The ALOs from urine are also phenotypically quite distinct from $A$. viridans (see Table 2). Therefore, on the basis of the present findings it is formally proposed that the ALOs of Christensen and associates be classified as a new species of the genus Aerococcus, as Aerococcus urinae (u.ri'nae: L. fem. n. urinae, pertaining to urine).

\section{Description of Aerococcus urinae sp. nov.}

Cells are Gram-positive, coccoid, occurring mostly in clusters but also in pairs and tetrads. Non-pigmented and non-motile. Microaerophilic. Catalase-negative. Growth does not occur at 10 and $45{ }^{\circ} \mathrm{C}$. Growth occurs in $6.5 \%$ $(\mathrm{w} / \mathrm{v}) \mathrm{NaCl}$, and on $5 \%(\mathrm{v} / \mathrm{v})$ horse blood agar, producing $\alpha$-haemolytic reaction. Acid is produced from $D$-arabitol (slow reaction), D-glucose, D-fructose, mannitol, ribose (slow reaction), sorbitol, sucrose and xylitol. Acid is not produced from amygdalin, arabinose, galactose, glycerol, glycogen, inositol, lactose, maltose, D-raffinose and trehalose. Hippurate is hydrolysed. Aesculin is not hydrolysed. $\beta$-Glucuronidase and leucine aminopeptidase positive. $\alpha$-Galactosidase, $\beta$-galactosidase, pyrrolidonylarylamidase, alkaline phosphatase and arginine dihydrolase negative. $\mathrm{H}_{2} \mathrm{~S}$ is not produced. Nitrate is not reduced to nitrite. The $\mathrm{G}+\mathrm{C}$ content of DNA is $44.4 \mathrm{~mol} \%$, as determined by melting temperature. Isolated from human sources (urinary tract specimens). The type strain is NCFB 2893 (NCTC 12142). 


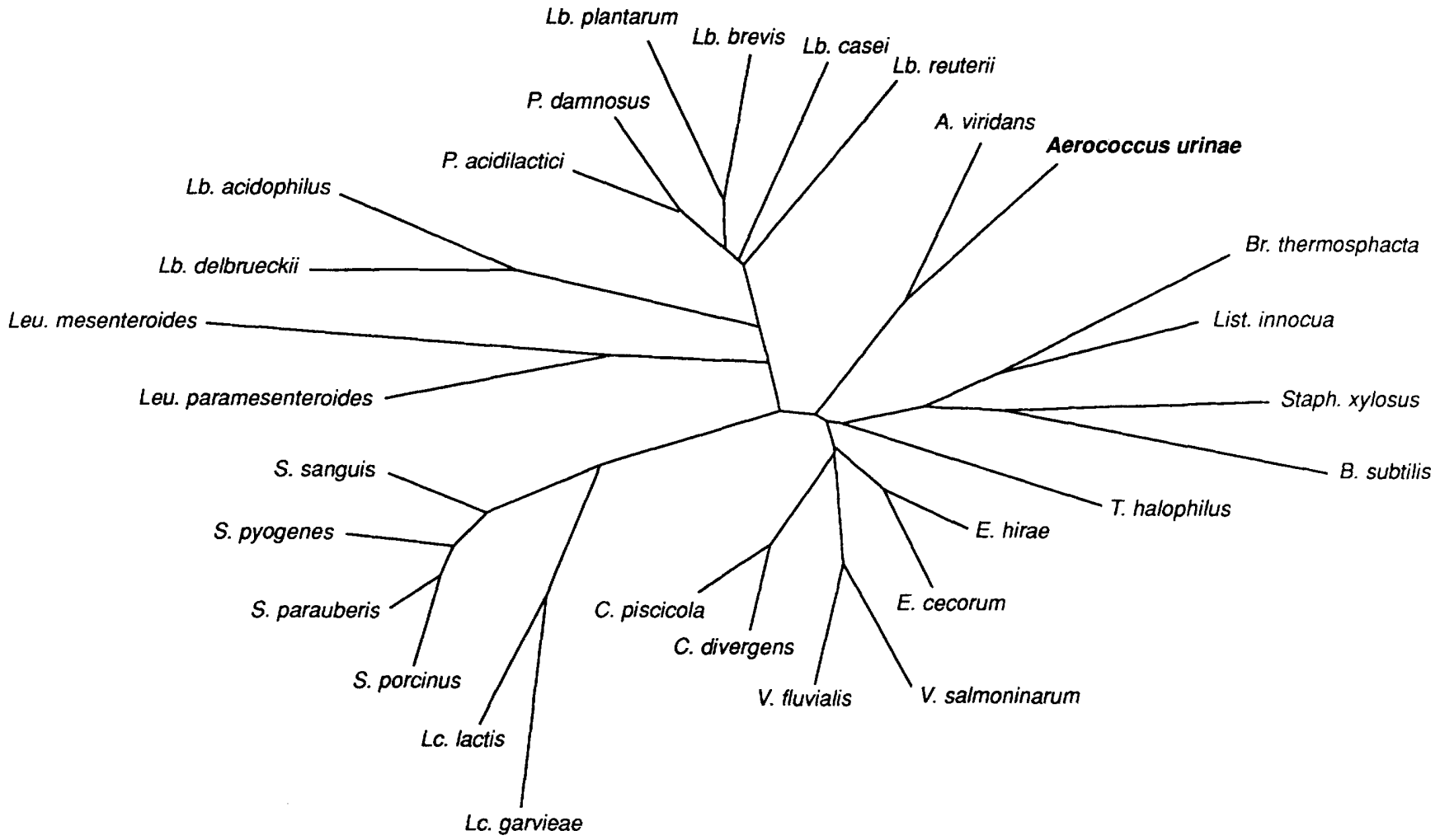

Fig. 2. Unrooted phylogenetic tree showing the position of Aerococcus urinae within a radiation of lactic acid bacteria. Genus abbreviations : A., Aerococcus; B., Bacillus; Br., Brochothrix; C., Carnobacterium ; E., Enterococcus ; Lb., Lactobacillus ; Lc., Lactococcus ; Leu., Leuconostoc; List., Listeria; P., Pediococcus; S., Streptococcus; Staph., Staphylococcus; T., Tetragenococcus; V., Vagococcus. Reference species corresponded to C. piscicola NCDO 2762 , E. hirae NCDO 1258 ${ }^{\mathrm{T}}$, Lb. brevis NCDO 1749 ${ }^{\mathrm{T}}$, Lb. casei $\mathrm{NCDO}_{161^{\mathrm{T}}}^{\mathrm{T}}$, Lb. delbrueckii NCDO $213^{\mathrm{T}}$, Lb. plantarum $\mathrm{NCDO} 1752^{\mathrm{T}}$, Lb. reuterii $\mathrm{NCDO} 2589^{\mathrm{T}}$, Lc. lactis $\mathrm{NCDO} 211^{\mathrm{T}}$, Leu. paramesenteroides NCDO $803^{\mathrm{T}}, P$. damnosus NCDO $1832^{\mathrm{T}}, S$. sanguis NCTC $7863^{\mathrm{T}}, S$. parauberis NCDO $651, S$. porcinus NCDO $600, T$. halophilus NCDO $1635^{\mathrm{T}}$, and $V$. salmoninarum NCFB $2777^{\mathrm{T}}$. Strain details of other species examined are given in Table 1.

We are grateful to Dr J. J. Christensen (Copenhagen) for the gift of cultures.

\section{References}

Bentley, R. W., Leigh, J. A. \& Collins, M. D. (1991). Intrageneric structure of Streptococcus based on comparative analysis of smallsubunit rRNA sequences. International Journal of Systematic Bacteriology 41, 487-494.

Bosley, G. S., Wallace, P. L., Moss, C. W., Steigerwalt, A. G., Brenner, D. J., Swenson, J. M., Hebert, G. A. \& Facklam, R. R. (1990). Phenotypic characterization, cellular fatty acid composition, and DNA relatedness of aerococci and comparison to related genera. Journal of Clinical Microbiology 28, 416-421.

Brosius, J., Palmer, M. L., KenNedy, J. P. \& Noller, H. F. (1978). Complete nucleotide sequence of a 16S ribosomal RNA gene from Escherichia coli. Proceedings of the National Academy of Sciences of the United States of America 75, 4801-4805.

Christensen, J. J., Korner, B. \& KJaegaARd, H. (1989). Aerococcuslike organism - an unnoticed urinary tract pathogen. APMIS 97, 539-546.

Christensen, J. J., Vibits, H., Ursing, F. \& Korner, B. (1991). Aerococcus-like organism, a newly recognized potential urinary tract pathogen. Journal of Clinical Microbiology 29, 1049-1053.
Collins, M. D., Ash, C., Farrow, J. A. E., Wallbanks, S. \& Williams, A. M. (1989). 16S ribosomal ribonucleic acid sequences analyses of lactococci and related taxa. Description of Vagococcus fluvialis gen. nov., sp. nov. Journal of Applied Bacteriology 67, 453460.

Collins, M. D., Williams, A. M. \& Wallbanks, S. (1990). The phylogeny of Aerococcus and Pediococcus as determined by $16 \mathrm{~S}$ rRNA sequence analysis: description of Tetragenococcus gen. nov. FEMS Microbiology Letters 70, 255-262.

Collins, M. D., Rodrigues, U., Ash, C., Aguirre, M., Farrow, J. A. E., Martinez Murcia, A., Phillits, B. A., Williams, A. M. \& WallbanKs, S. (1991). Phylogenetic analysis of the genus Lactobacillus and related lactic acid bacteria as determined by reverse transcriptase sequencing of $16 \mathrm{~S}$ rRNA. FEMS Microbiology Letters 77, 5-12.

Colman, G. (1967). Aerococcus-like organisms isolated from human infections. Journal of Clinical Pathology 20, 294-297.

Deibel, R. H. \& Niven, C. F. (1960). Comparative study of Gaffkya homari, Aerococcus viridans, tetrad-forming cocci from meat curing brines, and the genus Pediococcus. Journal of Bacteriology 79, 175180.

Embley, T. M., Smida, J. \& Stackebrandt, E. (1988). Reverse transcriptase sequencing of $16 \mathrm{~S}$ ribosomal RNA from Faenia rectivirgula, Pseudonocardia thermophila and Saccharopolyspora hirsuta, three wall IV actinomycetes which lack mycolic acids. Journal of General Microbiology 134, 961-966. 
Evans, J. B. (1986). Genus Aerococcus. In Bergey's Manual of Systematic Bacteriology, vol. 2, p. 1080. Edited by P. H. A. Sneath, N. S. Mair, M. E. Sharpe \& J. G. Holt. Baltimore: Williams \& Wilkins.

FACKLAM, R. R., Hollis, D. \& Collins, M. D. (1989). Identification of gram-positive coccal and coccobacillary vancomycin-resistant bacteria. Journal of Clinical Microbiology 27, 724-730.

Fitch, W. M. \& MaRgoliash, E. (1967). Construction of phylogenetic trees: a method based on mutation distances as estimated from cytochrome c sequences is a general applicability. Science 155, 279284.

GARVIE, E. I. (1978). Streptococcus raffinolactis (Orla-Jensen and Hansen): a group $\mathrm{N}$ streptococcus found in raw milk. International Journal of Systematic Bacteriology 28, 190-193.

HitCHNER, E. R. \& SNIESZKo, S. F. (1947). A study of a microorganism causing a bacterial disease of lobsters. Journal of Bacteriology $54,48$.

JANOSEK, J., ECKERT, J. \& HUdAC, A. (1980). Aerococcus viridans as a causative agent of infectious endocarditis. Journal of Clinical Pathology 20, 92-96.

Lane, D. J., Pace, B., Olsen, G. J., Stahl, D. A., Sogin, M. L. \& PACE, N. R. (1985). Rapid determination of 16S ribosomal RNA sequences for phylogenetic analyses. Proceedings of the National Academy of Sciences of the United States of America 82, 6955-6959.

Martinez Murcia, A. \& Collins, M. D. (1990). A phylogenetic analysis of the genus Leuconostoc based on reverse transcriptase sequencing of 16S rRNA. FEMS Microbiology Letters 70, 73-84.

Nathavitharana, K. A., Arseculeratne, S. N., Aponso, H. A., Vijeratnam, R., Jayasena, L. \& Navaratman, C. (1983). Acute meningitis in early childhood caused by Aerococcus viridans. British Medical Journal 286, 1248.
Neefs, J. M., Van de Peer, Y., Hendriks, L. \& DE Wachter, R. (1990). Compilation of small ribosomal subunit RNA sequences. Nucleic Acids Research Supplement 18, 2237-2242.

Parker, M. T. \& Ball, L. C. (1976). Streptococci and aerococci associated with systemic infection in man. Journal of Medical Microbiology 9, 275-302.

QUEEN, C. \& KORN, L. J. (1984). A comprehensive sequence analysis program for the IBM personal computer. Nucleic Acids Research 12 , 581-599.

SANGer, F., Nicklen, S. \& Coulson, A. R. (1977). DNA sequencing with chain-terminating inhibitors. Proceedings of the National Academy of Sciences of the United States of America 74, 54635467.

TAYloR, P. V. \& Trueblood, M. C. (1985). Septic arthritis due to Aerococcus viridans. Journal of Rheumatology 12, 1604-1605.

WIIK, R., TorsviK, V. \& EgIDIUs, E. (1986). Phenotypic and genotypic comparisons among strains of the lobster pathogen Aerococcus viridans and other marine Aerococcus viridans-like cocci. International Journal of Systematic Bacteriology 36, 431-434.

Williams, A. M., Rodrigues, U. M. \& Collins, M. D. (1991). Intrageneric relationships of enterococci as determined by reverse transcriptase sequencing of small subunit rRNA. Research in Microbiology 142, 67-74.

Williams, R. E. O., Hirsch, A. \& Cowan, S. T. (1953). Aerococcus, a new bacterial genus. Journal of General Microbiology 8, 475480.

YANG, D. \& WoESE, C. R. (1989). Phylogenetic structure of the leuconostocs: an interesting case of a rapidly evolving organism. Systematic and Applied Microbiology 12, 145-149. 